\title{
Common dietary flavonoids inhibit the growth of the intraerythrocytic malaria parasite Adele M Lehane ${ }^{1}$ and Kevin J Saliba*1,2
}

Address: ${ }^{1}$ School of Biochemistry and Molecular Biology, The Australian National University, Canberra, ACT 0200, Australia and ${ }^{2}$ Medical School, The Australian National University, Canberra, ACT 0200, Australia

Email: Adele M Lehane - adele.lehane@anu.edu.au; Kevin J Saliba* - kevin.saliba@anu.edu.au

* Corresponding author

Published: 18 June 2008

BMC Research Notes 2008, 1:26 doi:10.1 I86/1756-0500-1-26
Received: 28 March 2008

Accepted: 18 June 2008

This article is available from: http://www.biomedcentral.com/1756-0500/I/26

(c) 2008 Lehane and Saliba; licensee BioMed Central Ltd.

This is an Open Access article distributed under the terms of the Creative Commons Attribution License (http://creativecommons.org/licenses/by/2.0), which permits unrestricted use, distribution, and reproduction in any medium, provided the original work is properly cited.

\begin{abstract}
Background: Flavonoids are abundant plant phenolic compounds. More than 6000 have been identified to date, and some have been shown to possess antiparasitic activity. Here we investigate the effects of a range of common dietary flavonoids on the growth of two strains of the human malaria parasite Plasmodium falciparum.
\end{abstract}

Findings: A chloroquine-sensitive (3D7) and a chloroquine-resistant (7G8) strain of $P$. falciparum were tested for in vitro susceptibility to a range of individual dietary flavonoids and flavonoid combinations. Parasite susceptibility was measured in 96 -well plates over $96 \mathrm{~h}$ using a previously described $\left[{ }^{3} \mathrm{H}\right]$ hypoxanthine incorporation assay. Of the eleven flavonoids tested, eight showed antiplasmodial activity against the 3D7 strain (with $\mathrm{IC}_{50}$ values between II and $66 \mu \mathrm{M}$ ), and all showed activity against the $7 \mathrm{G} 8$ strain (with $\mathrm{IC}_{50}$ values between 12 and $76 \mu \mathrm{M}$ ). The most active compound against both strains was luteolin, with $\mathrm{IC}_{50}$ values of II $\pm I \mu \mathrm{M}$ and $\mathrm{I} 2 \pm \mathrm{I} \mu \mathrm{M}$ for 3D7 and 7G8, respectively. Luteolin was found to prevent the progression of parasite growth beyond the young trophozoite stage, and did not affect parasite susceptibility to the antimalarial drugs chloroquine or artemisinin. Combining low concentrations of flavonoids was found to produce an apparent additive antiplasmodial effect.

Conclusion: Certain common dietary flavonoids inhibit the intraerythrocytic growth of the 3D7 and $7 G 8$ strains of $P$. falciparum. Flavonoid combinations warrant further investigation as antiplasmodial agents.

\section{Findings}

Flavonoids are ubiquitous plant phenolic compounds that consist of two aromatic rings linked by a three-carbon bridge (see Table 1 for structure). More than 6000 flavonoids have been identified to date, and their essential functions in plants include regulating growth and providing protection against pathogens (reviewed in [1]). They are currently attracting significant medical interest because of their antioxidant, antitumor, antiinflamma- tory, antimicrobial and antiviral activities. Flavonoids are present in fruits, vegetables, wine, tea and coffee. Estimates of the daily intake of flavonoids in developed countries are as high as $1-2 \mathrm{~g}[1]$.

A number of reports have demonstrated growth inhibitory effects of flavonoids, particularly of the flavonol quercetin and of the flavone luteolin, on the protozoan parasite genera Toxoplasma [2], Trypanosoma [3] and Leish- 
Table I: Flavonoid $I_{50}$ values for growth inhibition of $P$. falciparum

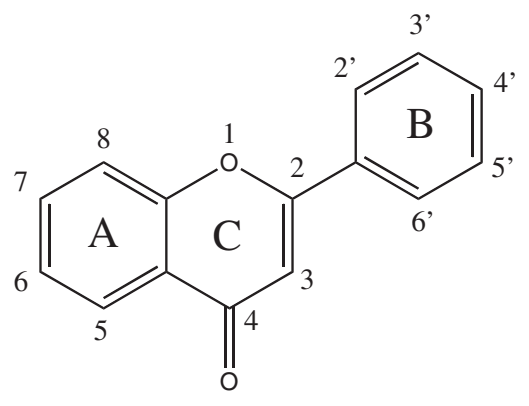

\begin{tabular}{|c|c|c|c|c|c|c|}
\hline \multirow[t]{2}{*}{ Class } & \multirow[t]{2}{*}{$\begin{array}{c}\text { Major food sources } \\
{[17]}\end{array}$} & \multirow[t]{2}{*}{ Flavonoid } & \multirow{2}{*}{$\begin{array}{l}\text { Chemical } \\
\text { substitutions/ } \\
\text { modifications }\end{array}$} & \multicolumn{2}{|c|}{$\begin{array}{c}\text { In vitro antiplasmodial activity }\left(\mathrm{IC}_{50}\right. \\
\mu \mathrm{M})^{\mathrm{a}}\end{array}$} & \multirow[t]{2}{*}{ LogD (pH 7.0) } \\
\hline & & & & 3D7 & $7 G 8$ & \\
\hline \multirow[t]{4}{*}{ Flavonols } & $\begin{array}{l}\text { Onions, kale, broccoli, } \\
\text { apples, cherries, } \\
\text { fennel, sorrel, berries, } \\
\text { tea }\end{array}$ & Kaempferol & $3,5,7,4^{\prime}-\mathrm{OH}$ & $33 \pm 7$ & $25 \pm 2$ & 2.40 \\
\hline & & Myricetin & $3,5,7,3^{\prime}, 4^{\prime}, 5^{\prime}-\mathrm{OH}$ & $40 \pm 10$ & $76 \pm 23$ & 2.06 \\
\hline & & Quercetin & $3,5,7,3^{\prime}, 4^{\prime}-\mathrm{OH}$ & $15 \pm 5$ & $14 \pm 1$ & 2.09 \\
\hline & & Isoquercitrin & $\begin{array}{c}\text { 3-gluc, } 5,7,3^{\prime}, 4^{\prime}- \\
\mathrm{OH}\end{array}$ & $66 \pm 10$ & $66 \pm 18$ & 1.59 \\
\hline \multirow[t]{5}{*}{ Flavones } & $\begin{array}{l}\text { Parsley, thyme, celery, } \\
\text { sweet red pepper }\end{array}$ & Acacetin & $5,7-\mathrm{OH} 4-\mathrm{OCH}_{3}$ & $>100$ & $13 \pm 2$ & 2.77 \\
\hline & & Apigenin & $5,7,4^{\prime}-\mathrm{OH}$ & $20 \pm 3$ & $13 \pm 2$ & 2.77 \\
\hline & & Baicalein & $5,6,7-\mathrm{OH}$ & $32 \pm 1$ & $21 \pm 6$ & 3.18 \\
\hline & & Chrysin & $5,7-\mathrm{OH}$ & $18 \pm 3$ & $22 \pm 4$ & 2.79 \\
\hline & & Luteolin & $5,7,3^{\prime}, 4^{\prime}-\mathrm{OH}$ & $11 \pm 1$ & $12 \pm 1$ & 2.62 \\
\hline Flavanones & Citrus fruits, prunes & Naringenin & $\begin{array}{c}5,7,4^{\prime}-\mathrm{OH}, \text { single } \\
\text { bond between } 2 \text { and } 3\end{array}$ & $>125$ & $71 \pm 10$ & 2.17 \\
\hline Isoflavones & Legumes & Genistein & $\begin{array}{l}5,7,4^{\prime}-\mathrm{OH}, \mathrm{B} \text { ring } \\
\text { attached to } 3\end{array}$ & $>50$ & $29 \pm 5$ & 1.53 \\
\hline Chloroquine & NA & NA & NA & $0.006 \pm 0.0003$ & $0.084 \pm 0.026$ & ND \\
\hline
\end{tabular}

a Values are the means ( \pm S.E.M.) of results from three independent experiments, each performed in duplicate or triplicate. Parasite susceptibility was measured in 96-well plates over $96 \mathrm{~h}$ using the $\left[{ }^{3} \mathrm{H}\right]$ hypoxanthine incorporation assay [19]. ${ }^{\mathrm{b}} \mathrm{LogD}$ (the octanol-water distribution coefficient) was predicted using PrologD (Pallas for Windows version 2.I, CompuDrug International Inc.). Good cell permeability requires a logD value of 2-5 [20]. NA, not applicable; ND, not determined.

mania [4-6]. The majority of studies involving flavonoids and malaria describe the antiplasmodial activity-guided fractionation of plants (including species used in traditional medicine). Flavonoids (usually along with other compounds) have been identified in the antiplasmodial fractions of many plants, and in some cases have been shown to possess antiplasmodial activity when isolated [4,7-12]. Despite this, until very recently only the structurally distinct chalcone subclass of flavonoids attracted much further investigation.

In this study, the flavanone naringenin, the isoflavone genistein, and a range of flavonols (kaempferol, myricetin, quercetin and isoquercitrin) and flavones (acacetin, apigenin, baicalein, chrysin and luteolin) were tested against a chloroquine-sensitive (3D7) and a chloroquineresistant (7G8) strain of Plasmodium falciparum. The flavo- noids were purchased from Sigma-Aldrich (Australia), and purities were $\geq 95 \%$ except for isoquercitrin which was $\geq 90 \%$. A recent study demonstrated the in vitro antiplasmodial activities of a number of these compounds [13]; we confirm and extend these findings with different P. falciparum strains.

Of the eleven flavonoids tested, eight showed antiplasmodial activity against the $3 \mathrm{D} 7$ strain, with mean $\mathrm{IC}_{50}$ values in the range 11-66 $\mu \mathrm{M}$ (Table 1). The remaining three (acacetin, naringenin and genistein) did not achieve 50\% parasite killing at the highest concentrations tested (which varied according to solubility in aqueous media; DMSO concentrations were kept $\leq 0.1 \%$ to prevent any effect on parasite growth). All the flavonoids tested showed measurable activity against the chloroquine-resistant 7G8 strain, with $\mathrm{IC}_{50}$ values between 12 and $76 \mu \mathrm{M}$. The most 
active compound in both strains was luteolin, with $\mathrm{IC}_{50}$ values of $11 \pm 1 \mu \mathrm{M}$ and $12 \pm 1 \mu \mathrm{M}$ for $3 \mathrm{D} 7$ and $7 \mathrm{G} 8$, respectively (Table 1 ).

Marked differences in the susceptibilities of the two strains to some flavonoids (most notably to acacetin) were observed in this study and in that of Tasdemir et al. [13]. In both studies, the chloroquine-resistant strain was generally more susceptible to growth inhibition. Whether enhanced sensitivity to some flavonoids relates to the chloroquine resistance phenotype or other difference(s) in genetic background is not known. These strain differences make structure-activity determinations difficult. Furthermore, potential differences in cell permeability should also be considered. The higher antiplasmodial activity of quercetin $(\log D 2.09)$ compared to the quercetin glucoside isoquercitrin $(\log \mathrm{D} 1.59)(\mathrm{P}=0.002$, paired t-test) could be a result of better cell permeability. Similarly, the flavanone naringenin ( $\log D 2.17)$ differs from apigenin ( $\log \mathrm{D} 2.77$ ) only in the absence of a double bond in the $C$ ring but is much less active $(P=0.02$, paired t-test for 7G8). Also, the isoflavone genistein $(\log D 1.53)$ differs from apigenin $(\log D 2.77)$ only in that the $\mathrm{B}$ ring is attached to carbon 3 of the $\mathrm{C}$ ring rather than carbon 2 , and is less active against both strains $(P=0.03$, paired $t-$ test for 7G8). However, the testing of a number of additional flavonoids would be required to conclude that differences in activities are a result of different cell permeabilities.

The effect of a number of the flavonoids tested here on the viability of two normal (non-cancerous) human cell lines has been reported [14]. In the cases of apigenin, kaempferol, luteolin and quercetin, the $\mathrm{IC}_{50}$ values against both strains of $P$. falciparum are at least 4 -fold lower than the $\mathrm{IC}_{50}$ values reported against both human cell lines. Naringenin has relatively low activity against $P$. falciparum (Table 1) and human cells [14]. In addition, MamaniMatsuda et al. [3] investigated quercetin toxicity towards haemopoietic cells and found that the $\mathrm{IC}_{50}$ value was greater than $100 \mu \mathrm{M}$ (> 6-fold higher than the $\mathrm{IC}_{50}$ against $P$. falciparum reported here; Table 1$)$.

To investigate which stage of the parasite's intraerythrocytic lifecycle is inhibited by flavonoids, we prepared Giemsa-stained 7G8-infected erythrocyte smears at various time points following the addition of $20 \mu \mathrm{M}$ luteolin $\left(\sim 2 \times \mathrm{IC}_{50}\right)$. Figure 1 reveals that luteolin does not inhibit the ring stage of the parasite but prevents the progression

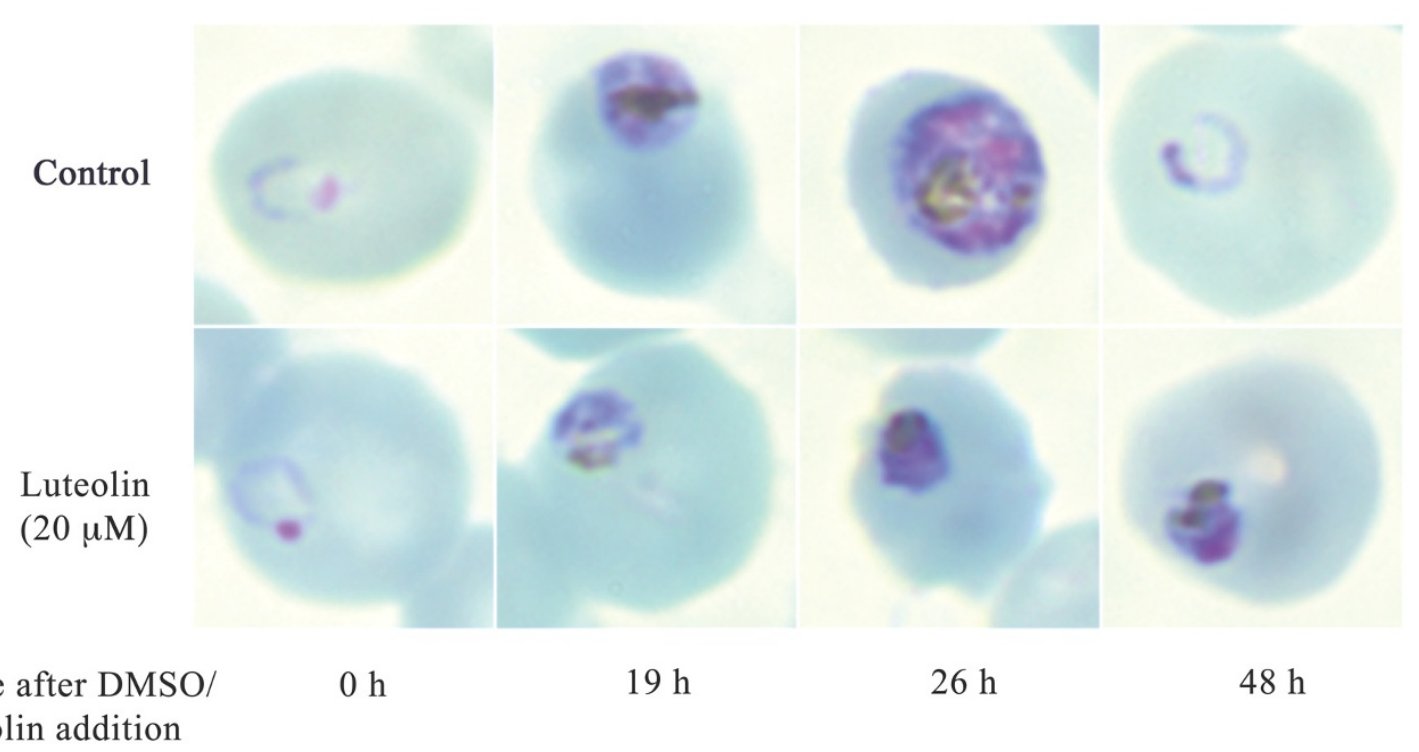

\section{Figure I}

The effect of luteolin on the intraerythrocytic growth of $\boldsymbol{P}$. falciparum. Giemsa-stained smears were prepared at 0 , 19, 26 and $48 \mathrm{~h}$ after the addition of luteolin $(20 \mu \mathrm{M})$ dissolved in DMSO or an equal volume of DMSO (control; $0.025 \%$ DMSO) to 7G8-infected erythrocytes (I\% parasitemia, 2\% hematocrit). While control parasites developed into mature trophozoites $(26 \mathrm{~h})$ that subsequently gave rise to daughter parasites $(48 \mathrm{~h})$, the growth of luteolin-treated parasites was arrested at the young trophozoite stage. Luteolin-treated parasites did not give rise to daughter parasites, resulting in a reduced parasitemia compared to the control at the $48 \mathrm{~h}$ time point. 
of parasite growth beyond the young trophozoite stage. The parasites are therefore unable to complete a full intraerythrocytic cycle. An arrest in cell cycle progression has also been observed for Leishmania donovani promastigotes treated with luteolin or quercetin [5]. Furthermore, quercetin has been shown to inhibit bradyzoite development in Toxoplasma gondii [2]. Further studies are required to elucidate the mechanism by which flavonoids arrest parasite growth.

There have been several reports of flavonoids showing synergistic or antagonistic activities with various antiparasitic drugs $[10,15,16]$. We therefore tested the effect of luteolin (at concentrations of $2.5 \mu \mathrm{M}, 5 \mu \mathrm{M}, 10 \mu \mathrm{M}$ and 20 $\mu \mathrm{M})$ on the susceptibility of 7G8 to two important antimalarial drugs, chloroquine and artemisinin. Luteolin did not significantly affect the $\mathrm{IC}_{50}$ values of either drug (not shown). Therefore, luteolin should not antagonise the activities of chloroquine or artemisinin if used in combination therapy.

The finding that common dietary compounds display antiplasmodial activity raises the intriguing question of whether a plant-based diet could play a role in malaria prevention or lessen disease severity. To investigate whether combinations of dietary flavonoids could display an additive effect, we combined equimolar amounts of the eleven flavonoids tested in this study such that the highest concentration of each was not toxic to the parasite $(4 \mu \mathrm{M})$. This resulted in $50 \%$ growth inhibition against $7 \mathrm{G} 8$ at a total flavonoid concentration of $31 \pm 3 \mu \mathrm{M}$ (Figure $2 \mathrm{~A}$ ), a value similar to the mean $\mathrm{IC}_{50}$ value for the eleven flavonoids $(33 \mu \mathrm{M})$. At this total flavonoid concen- tration, each individual flavonoid is present at a concentration of only $2.8 \mu \mathrm{M}$. We then combined equimolar amounts of three of the most active compounds, luteolin, quercetin and apigenin, such that the highest total flavonoid concentration was $44 \mu \mathrm{M}$ (i.e. the same maximum total flavonoid concentration used when 11 flavonoids were combined). The combination of these three flavonoids gave an $\mathrm{IC}_{50}$ value of $21 \pm 2 \mu \mathrm{M}$ (Figure $2 \mathrm{~B}$ ), somewhat higher than their mean $\mathrm{IC}_{50}$ value $(13 \mu \mathrm{M})$. However, at this total flavonoid concentration each individual flavonoid is only present at a concentration of 7 $\mu \mathrm{M}$, which is lower than individual $\mathrm{IC}_{50}$ values. Adding a less active flavonoid (naringenin) to this combination, while maintaining the same maximum combined flavonoid concentration of $44 \mu \mathrm{M}$ (i.e. each individual flavonoid was now present at a maximum concentration of 11 $\mu \mathrm{M})$, increased the $\mathrm{IC}_{50}$ value close to the new mean value (combination $\mathrm{IC}_{50}=24 \pm 2 \mu \mathrm{M}$, average $\mathrm{IC}_{50}=28 \mu \mathrm{M}$; Figure $2 \mathrm{C}$ ). While the data are consistent with the flavonoids having an additive antiplasmodial effect, the possibility that there is a combination of synergistic and antagonistic effects between some of the individual flavonoids in these combinations that results in an apparent additive effect cannot be excluded.

The concentrations of diet-derived individual flavonoids in plasma are unlikely to reach those required for complete parasite killing. The extent to which flavonoids are absorbed from the gastrointestinal tract depends on factors such as the flavonoid itself and the dietary source $[1,17,18]$. Another important issue is the metabolism of flavonoids in vivo to form potentially less active conjugates [18]. Thus, it will be important to investigate the
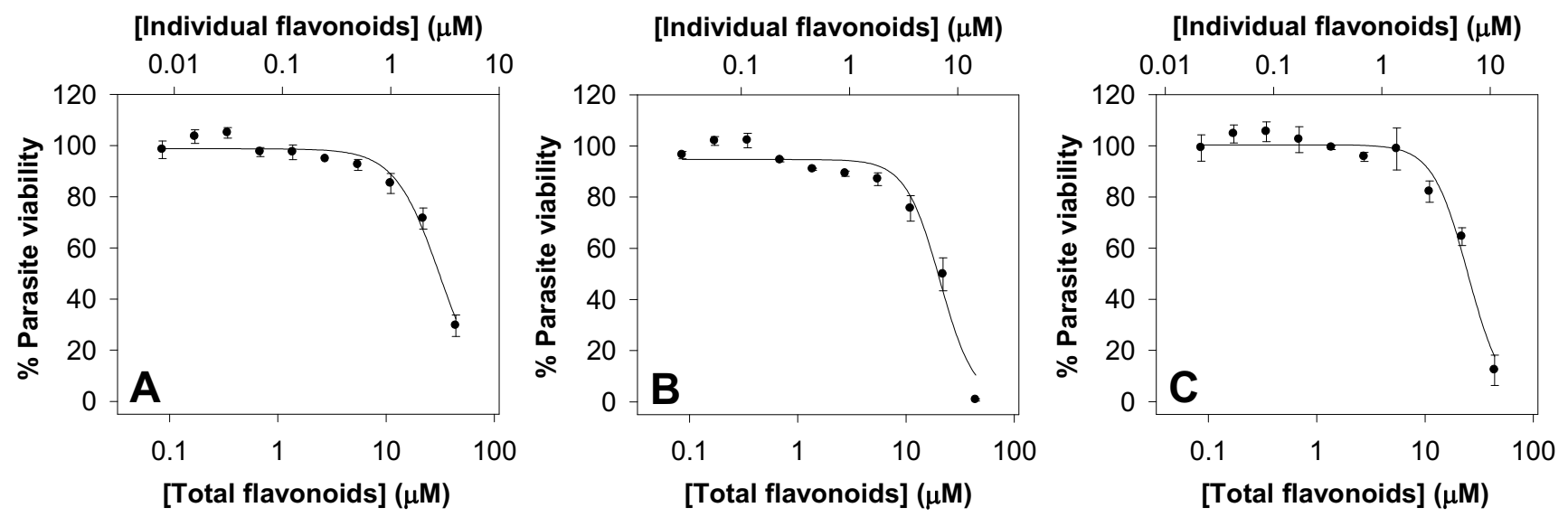

Figure 2

The effects of flavonoid combinations on the proliferation of the $\mathbf{7 G 8}$ strain of $\boldsymbol{P}$. falciparum. Equimolar amounts of (A) the eleven flavonoids tested in this study, (B) apigenin, luteolin and quercetin, and (C) apigenin, luteolin, naringenin and quercetin, were combined. The data are averaged from three independent experiments, each performed in duplicate or triplicate. Error bars represent S.E.M. 
activities of the main conjugates of promising antiplasmodial flavonoids. Nevertheless, our study raises the possibility of using clinically relevant, non-toxic concentrations of flavonoid combinations as antiplasmodial agents.

\section{Competing interests}

The authors declare that they have no competing interests.

\section{Authors' contributions}

AML participated in the design of the study, performed the experiments and data analysis and drafted the manuscript. KJS participated in the design of the study and helped to draft the manuscript. Both authors read and approved the final manuscript.

\section{Acknowledgements}

The authors are grateful to AP Wasson for helpful discussions and to the Canberra branch of the Australian Red Cross Blood Service for the provision of human blood.

\section{References}

I. Havsteen BH: The biochemistry and medical significance of the flavonoids. Pharmacol Ther 2002, 96(2-3):67-202.

2. Weiss LM, Ma YF, Takvorian PM, Tanowitz HB, Wittner M: Bradyzoite development in Toxoplasma gondii and the hsp70 stress response. Infect Immun 1998, 66(7):3295-3302.

3. Mamani-Matsuda M, Rambert J, Malvy D, Lejoly-Boisseau H, Daulouede S, Thiolat D, Coves S, Courtois P, Vincendeau P, Mossalayi MD: Quercetin induces apoptosis of Trypanosoma brucei gambiense and decreases the proinflammatory response of human macrophages. Antimicrob Agents Chemother 2004, 48(3):924-929.

4. Kirmizibekmez H, Calis I, Perozzo R, Brun R, Donmez AA, Linden A, Ruedi $P$, Tasdemir $D$ : Inhibiting activities of the secondary metabolites of Phlomis brunneogaleata against parasitic protozoa and plasmodial enoyl-ACP Reductase, a crucial enzyme in fatty acid biosynthesis. Planta Med 2004, 70(8):7II-7II.

5. Mittra B, Saha A, Chowdhury AR, Pal C, Mandal S, Mukhopadhyay S, Bandyopadhyay S, Majumder HK: Luteolin, an abundant dietary component is a potent anti-leishmanial agent that acts by inducing topoisomerase II-mediated kinetoplast DNA cleavage leading to apoptosis. Mol Med 2000, 6(6):527-54I.

6. Sen G, Mandal S, Saha Roy S, Mukhopadhyay S, Biswas T: Therapeutic use of quercetin in the control of infection and anemia associated with visceral leishmaniasis. Free Radic Biol Med 2005, 38(9): 1257-। 264.

7. Kraft C, Jenett-Siems K, Siems K, Gupta MP, Bienzle U, Eich E: Antiplasmodial activity of isoflavones from Andira inermis. J Ethnopharmacol 2000, 73(I-2): | 3|-|35.

8. Kraft C, Jenett-Siems K, Siems K, Jakupovic J, Mavi S, Bienzle U, Eich $\mathrm{E}$ : In vitro antiplasmodial evaluation of medicinal plants from Zimbabwe. Phytother Res 2003, 17(2): I23-128.

9. Kraft C, Jenett-Siems K, Siems K, Solis PN, Gupta MP, Bienzle U, Eich E: Andinermals A-C, antiplasmodial constituents from Andira inermis. Phytochemistry 200I, 58(5):769-774.

10. Liu KCSC, Yang SL, Roberts MF, Elford BC, Phillipson JD: Antimalarial activity of Artemisia annua flavonoids from whole plants and cell cultures. Plant Cell Reports I992, I I(I 2):637.

1I. Yenesew A, Derese S, Irungu B, Midiwo JO, Waters NC, Liyala P, Akala $\mathrm{H}$, Heydenreich M, Peter MG: Flavonoids and isoflavonoids with antiplasmodial activities from the root bark of Erythrina abyssinica. Planta Med 2003, 69(7):658-66I.

12. Yenesew A, Induli M, Derese S, Midiwo JO, Heydenreich M, Peter MG, Akala H, Wangui J, Liyala P, Waters NC: Anti-plasmodial flavonoids from the stem bark of Erythrina abyssinica. Phytochemistry 2004, 65(22):3029-3032.
13. Tasdemir D, Lack G, Brun R, Ruedi P, Scapozza L, Perozzo R: Inhibition of Plasmodium falciparum Fatty Acid Biosynthesis: Evaluation of FabG, FabZ, and Fabl as Drug Targets for Flavonoids. J Med Chem 2006, 49( I I):3345-3353.

14. Matsuo M, Sasaki N, Saga K, Kaneko T: Cytotoxicity of flavonoids toward cultured normal human cells. Biol Pharm Bull 2005, 28(2):253-259.

15. Elford BC, Roberts MF, Phillipson JD, Wilson RJ: Potentiation of the antimalarial activity of qinghaosu by methoxylated flavones. Trans $R$ Soc Trop Med Hyg I 987, 8 I (3):434-436.

16. Perez-Victoria JM, Perez-Victoria FJ, Conseil G, Maitrejean M, Comte G, Barron D, Di Pietro A, Castanys S, Gamarro F: High-affinity binding of silybin derivatives to the nucleotide-binding domain of a Leishmania tropica P-glycoprotein-like transporter and chemosensitization of a multidrug-resistant parasite to daunomycin. Antimicrob Agents Chemother 200I, 45(2):439-446.

17. Ross JA, Kasum CM: Dietary flavonoids: bioavailability, metabolic effects, and safety. Annu Rev Nutr 2002, 22:19-34.

18. Walle T: Absorption and metabolism of flavonoids. Free Radic Biol Med 2004, 36(7):829-837.

19. Desjardins RE, Canfield CJ, Haynes JD, Chulay JD: Quantitative assessment of antimalarial activity in vitro by a semiautomated microdilution technique. Antimicrob Agents Chemother 1979, 16(6):710-718.

20. Lipinski CA, Lombardo F, Dominy BW, Feeney PJ: Experimental and computational approaches to estimate solubility and permeability in drug discovery and development settings. Adv Drug Delivery Rev 1997, 23(I-3):3.
Publish with BioMed Central and every scientist can read your work free of charge

"BioMed Central will be the most significant development for disseminating the results of biomedical research in our lifetime. "

Sir Paul Nurse, Cancer Research UK

Your research papers will be:

- available free of charge to the entire biomedical community

- peer reviewed and published immediately upon acceptance

- cited in PubMed and archived on PubMed Central

- yours - you keep the copyright
BioMedcentral 